\title{
Evolution of the climatic tolerance and postglacial range changes of the most primitive orchids (Apostasioideae) within Sundaland, Wallacea and Sahul
}

\author{
Marta Kolanowska ${ }^{\text {Corresp., }}{ }^{1,2}{ }^{2}$, Katarzyna Mystkowska ${ }^{1}$ ， Marta Kras $^{1}$, Magdalena Dudek $^{1}$, Kamil Konowalik $^{3}$ \\ 1 Department of Plant Taxonomy and Nature Conservation, University of Gdansk, Gdańsk, Poland \\ 2 \\ 3 Department of Plant Biology, Institute of Biology, Wrocław University of Environmental and Life Sciences, Wrocław, Poland \\ Corresponding Author: Marta Kolanowska \\ Email address: martakolanowska@wp.pl
}

The location of possible glacial refugia of six Apostasioideae representatives is estimated based on ecological niche modeling analysis. The distribution of their suitable niches during the last glacial maximum (LGM) is compared with their current potential and documented geographical ranges. The climatic factors limiting the studied species occurrences are evaluated and the niche overlap between the studied orchids is assessed and discussed. The predicted niche occupancy profiles and reconstruction of ancestral climatic tolerances suggest high level of phylogenetic niche conservatism within Apostasioideae. 


\section{Evolution of the climatic tolerance and postglacial range}

\section{2 changes of the most primitive orchids (Apostasioideae) within}

\section{Sundaland, Wallacea and Sahul}

4

5 Marta Kolanowska ${ }^{1,2}$, Katarzyna Mystkowska ${ }^{1}$, Marta Kras ${ }^{1}$, Magdalena Dudek ${ }^{1}$, Kamil Konowalik ${ }^{3}$

$6{ }^{1}$ Department of Plant Taxonomy and Nature Conservation, University of Gdansk, Wita Stwosza 59, PL-

7 80-308 Gdańsk, Poland

$8{ }^{2}$ Department of Biodiversity Research, Global Change Research Institute AS CR, Bělidla 4a. 60300 Brno,

9 Czech Republic

${ }^{3}$ Department of Plant Biology, Institute of Biology, Wrocław University of Environmental and Life

Sciences, Kożuchowska 5b, 51-631 Wrocław, Poland

12

Corresponding author:

Marta Kolanowska ${ }^{1}$

Wita Stwosza 59, PL-80-308 Gdańsk, Poland

Email address: martakolanowska@wp.pl 


\section{Abstract}

The location of possible glacial refugia of six Apostasioideae representatives is estimated based on ecological niche modeling analysis. The distribution of their suitable niches during the last glacial maximum (LGM) is compared with their current potential and documented geographical ranges. The climatic factors limiting the studied species occurrences are evaluated and the niche overlap between the studied orchids is assessed and discussed. The predicted niche occupancy profiles and reconstruction of ancestral climatic tolerances suggest high level of phylogenetic niche conservatism within Apostasioideae.

The orchid subfamily Apostasioideae includes only two genera, Apostasia and Neuwiedia which are restricted in their distribution to Asia and Australia. They are small to medium-sized terrestrial plants producing elongated, fibrous roots. Their leathery, plicate leaves are spirally arranged, spreading or suberect. Inflorescences are terminal, racemose, few- to manyflowered. Flowers are actinomorphic to slightly zygomorphic, with lip similar to petals or slightly broader (Xinqi, Gale \& Cribb, 2009). In apostasioid orchids the column part is usually obscure. Two or three fertile anthers, representing the median of the outer whorl, and the laterals of the inner whorl are present. All stigma lobes are similar to each other in size and shape. Pollen grains do not form any pollinia (Szlachetko \& Rutkowski, 2000).

Apostasioideae have been intensively studied in the contexts of their taxonomic affinities (Kocyan \& Endress, 2001), phylogenetics (Judd, Stern \& Cheadle, 1993; Kocyan et al., 2004), 
anatomy (Stern \& Cheadle, 1993), mycorrhizal associations (Yukawa et al., 2009) and genome size (Jersáková et al., 2013). So far, however no research on their biogeography has been conducted.

The divergence between Apostasioideae and other orchids occurred in the Mesozoic. The age of ancestor of this subfamily is estimated at 41-49 Ma (Ramírez et al., 2007; Gustafsson, Verola \& Antonelli, 2010) which was a time of important geological events. The occurrence of apostasioids has been reported from India, Nepal, Bhutan, Japan, south-east Asia, New Guinea and northern Australia (Xinqi, Gale \& Cribb, 2009). Their geographical range significantly overlap one of the least understood regions of the World. The enormous geological activity of this area has created a complex, fragmented pattern of numerous islands. During the frequent past glacial periods numerous islands were connected by dry land forming two large masses called Sundaland and Sahul. These two areas are separated by Wallacea, a group of mainly Indonesian islands which were never bridged by dry land during glaciation ( $O^{\prime}$ Connell, Allen \& Hawkes, 2010). Research by van Hinsbergen et al. (2012) indicated that a collision of an extended microcontinental fragment and continental Asia occurred approximately $50 \mathrm{Ma}$, and it was followed by a continent to continent collision about $25 \mathrm{Ma}$. The dispersal of Indian floristic elements in Southeast Asia estimated based on palynological data (Morley, 1998) took place in the middle Eocene (50-39 Ma). Moreover, in the late Eocene the Tasmanian Gateway opened (Exon et al. 2002). The paleogeography varied with eustatic sea level fluctuations, however, from the Eocene to Early Miocene most of Sundaland was terrestrial with volcanic areas at the southern margin. Australia began to collide with south-eastern Sundaland about 23 million years ago closing the former deep ocean separating the two continents (Hall 2013). The 
62 Neogene history of the SE Asian gateway is a complex history of rapid changes in tectonics,

63

64

65

66

67

68

69

topography and land/sea distributions (Hall et al., 2011). Simulations of the paleoclimate at the Last Glacial Maximum (LGM; about 22000 years ago) indicated that the majority of Sundaland was well within climatic envelope for tropical everwet forest (Cannon et al., 2009)

As mentioned before, biogeographical research on Apostasioideae, especially those on their history were not published. The deficiencies in the knowledge of the distribution of glacial refugia and further migration concern numerous herbaceous tropical plants which are often absent in fossil material. In such cases the analysis of postgalcial history usually based on molecular analyses (e.g. Nordström \& Hedrén, 2008). However, the results of these research are not always consistent with the distribution of their suitable climatic niches in glacial and postglacial period (Naczk \& Kolanowska, 2015). For tropical plants it is also difficult to estimate their ecological tolerances for climatic factors based on traditional field observations as well as to select crucial variables limiting their occurrence. For that reason the ecological differences between numerous closely related species remain unknown.

The aim of the present study was to combine results of classical herbarium studies with modern computer tools and molecular data to reconstruct postgalcial history of Apostasioideae representatives and to evaluate variation in their preferred climatic niches. It is particularly important for endangered plants since the knowledge of their past may be a guidance how the organisms will adapt in response to global climate change in the future. The recognition of the niche conservatism within closely related species is also essential for understanding their evolution. 
83 Our research focused on estimation of the location of possible glacial refugia of studied orchids

84

85

during the LGM and to evaluate postglacial changes in the distribution of their ecological niches using ecological niche modeling (ENM) analysis. The results of ENM were combined with the phylogenetic study to reconstruct ecological tolerances of the studied species ancestors and to visualize evolution of the climatic tolerances within Apostasioideae. Additionally, the differences between climatic niches occupied by representatives of Apostasia and Neuwiedia and climatic factors limiting their occurrence were evaluated.

\section{Material and methods}

\section{Data sources}

A database of the sites of Apostasioideae representatives was prepared based on the examination of herbarium specimens stored in $\mathrm{BM}, \mathrm{K}, \mathrm{MO}$, and $\mathrm{P}$, as well as the electronic databases of AAU, BRI, CANBR, CNS, NOCC, SCBI, SING, US and the Swiss Orchid Foundation. The herbaria acronyms follow Index Herbariorum (Thiers, 2015). Only the sites that could be precisely placed on the map were used in our analyses. The process of georeferencing followed Hijmans et al. (1999). The geographic coordinates provided on the herbarium sheet labels were verified. If there was no georeferencing information on the herbarium sheet label, we followed the description of the collection place and assigned coordinates as precisely as possible.

We did not find enough material (occurrence data) to conduct analysis for Apostasia latifolia Rolfe, Apostasia parvula Schltr., A. ramifera S.C.Chen \& K.Y.Lang, A. shenzhenica Z.J.Liu \& L.J.Chen, Neuwiedia elongata de Vogel, N. griffithii Rchb.f., N. inae de Vogel, N. malipoensis 
104 Z.J.Liu, L.J.Chen \& K.Wei Liu, or N. siamensis de Vogel. We gathered a total of 179 occurrence

105 records of three Apostasia and three Neuwiedia species (S1 Table): 27 of Apostasia nuda R. Br., 10622 of $A$. odorata Blume, 80 of $A$. wallichii R. Br., eight of Neuwiedia borneensis de Vogel, 24 of

107 N. veratrifolia Blume, and 18 of $N$. zollingeri Rchb. f. To reduce sample bias we applied spatial

108 filtering (Boria et al. 2014). From a total of 179 records we randomly removed sites of each

109 species that were within $25 \mathrm{~km}$ of one another. The final database included 13 sites of

110 Apostasia nuda, 13 of $A$. odorata, 41 of $A$. wallichii, four of Neuwiedia borneensis, 18 of $N$.

111 veratrifolia, and 10 of $N$. zollingeri.

112

113 Ecological Niche Modeling

114 The ecological niche modelling was conducted using the maximum entropy method

115 implemented in MaxEnt version 3.3.2 (Phillips, Dudík \& Schapire, 2004; Phillips, Anderson \&

116 Schapire, 2006; Elith et al., 2011) based on the species presence-only observations. From 19

117 climatic variables ("bioclims", Table 1 ) in 2.5 arc minutes ( $\pm 20 \mathrm{~km} 2$ at the equator) developed

118 by Hijmans et al. (2005) we removed seven "bioclims" due to their significant correlation

119 (above 0.9) as evaluated by the Pearson's correlation coefficient calculation computed using

120 ENMTools v1.3. The following variables were excluded from the dataset: bio6, bio7, bio9, bio10,

121 bio11, bio16 and bio17. As it was suggested that using a restricted area in ENM analysis is more

122 reliable than calculating habitat suitability on the global scale (Barve et al., 2011) the area of

123 our analysis was restricted to longitude $88^{\circ}-190^{\circ} \mathrm{E}$ and latitude $53^{\circ} \mathrm{S}-47.8^{\circ} \mathrm{N}$. The maximum

124 iterations was set to 10000 and the convergence threshold to 0.00001 . The "random seed"

125 option which provided the random test partition and background subset for each run was 
126

127

128

129

130

131

132

133

134

135

136

137

138

139

140

141

142

143

144

145

146

147

applied. The run was performed as a bootstrap with 1000 replicates, and the output was set to

logistic. The analogical settings were used in the modelling for LGM. The bioclimatic data for this time period were developed and mapped (CCSM4) by Coupled Model Intercomparison Project Phase 5 (CMIP5; Taylor, Stouffer \& Meehl, 2012). All operations on GIS data were carried out on ArcGis 9.3 (ESRI).

The evaluation of the models was done using the most common metric - area under the curve (AUC; Mason \& Graham, 2002) which was calculated by the Maxent application automatically. The niche overlap between the studied species was calculated using ENMTools v1.3 (Warren, Glor \& Turelli, 2010).

\section{Evolution of climatic tolerance and predicted niche occupancy (PNO)}

To visualize niche evolution for Apostasioideae the ancestral tolerances were pictured on a phylogenetic tree. To construct the tree for taxa included in the ecological niche modeling sequences from ITS, matK and trnL available from GenBank (S2 Table) were aligned in Mafft 6.833b (Katoh \& Toh, 2008) and Gapcoder (Young \& Healy, 2003) was used to code indels. Aligments were merged and a Bayesian phylogenetic analysis was performed in MrBayes 3.2.1 (Ronquist et al., 2012). In the nucleotide part for each marker separately, a model from the best selection according to AIC implemented in jModelTest 2.1.1 (Darriba et al., 2012) was used. For the binary coded gaps, a Jukes-Cantor model (Jukes \& Cantor, 1969) was used. 15,000,000 generations were performed in two runs discarding the first $25 \%$ as the burnin fraction and sampling every 1000th tree. As an outgroup Cypripedium subtropicum was used. To estimate node ages function chronos in package "ape" was used (Paradis et al. 2004) applying lambda 
148 set to 20 . In this function branch lengths elucidate mean numbers of substitutions and node

149 ages are estimated using semi-parametric method based on penalized likelihood (Sanderson,

150 2002; Paradis et al., 2004). As calibration points splits between Apostasioideae and Cypripedium

151 (80 Mya), and Apostasia and Neuwiedia (43 Mya) were used following published divergence

152 times (Gustafsson et al., 2010). To reconstruct ancestral ecological tolerances and predicted

153 niche occupany profiles (PNOs) the Phyloclim package was used (Heibl \& Calenge, 2013) which

154 implements the methodology originally developed by Evans et al. (Evans et al., 2009). PNO

155 profile takes into account species probability distribution derived from ecological niche

156 modeling and compiles a response to a particular environmental variable for each species.

157 Ancestral ecological tolerances are computed from the phylogenetic tree and PNO using

158 nonparametric approach and ancestral character estimation (Paradis et al. 2004, Evans et al., 159 2009).

161 Results

162 Models evaluation

163 All the created models received high AUC scores of $0.898-0.989$. These results are consistent

164 with the outcomes of previous studies which indicated the reliable performance of this method

165 for developing ecological niche models based exclusively on presence-only data (Elith et al., 166 2006).

167

\section{Glacial refugia}


169 The ENM analysis indicated eastern Mindanao, Borneo, Sumatra, eastern Sunda, and northern

170 Sahul as areas suitable for the occurrence of Apostasia nuda. The potential refugia of $A$.

171 odorata are widely distributed along the coast of Sahul and Sunda, as well as between those

172 shelves. The highly suitable niches of Apostasia wallichii were limited to the north-eastern part

173 of Sunda. The created models indicated an even smaller potential coverage area of the glacial

174 refugia of Neuwiedia borneensis. The most suitable niches were limited to numerous small

175 islands north-east of Sahul. Some less appropriate habitats could be found in Borneo and south

176 of this region, as well as along northern Sauhl. The refugia of $N$. veratrifolia were widely

177 distributed in Sunda, Sumatra, Java, Mindanao, and northern Sahul. Suitable niches of

178 Neuwiedia zollingeri during LGM were located in islands west of Sunda, eastern Mindanao,

179 Sulawesi and smaller islands north-east of Sahul. Figs 1-2.

\section{Current potential range}

182 Currently the most suitable niches of Apostasia nuda are located in Peninsular Malaysia,

Borneo, Sumatra, western Mindanao, Sulawesi, Halmahera, north-western New Guinea and

New Britain. The potential range of $A$. odorata is very wide within the studied area. No suitable

climatic conditions were indicated by the created models in the areas of higher elevation in continental south-east Asia and the central part of New Guinea. In Australia the appropriate niches are located in Tasmania, in Cape York Peninsula, and along the northern, south-eastern and south-western coasts. Some areas characterized by the climatic conditions suitable for this species are also located in New Zealand. The potential range of $A$. wallichii includes the coasts of Thailand, Cambodia and Vietnam. It may also occur in Burma, southern Sumatra, Peninsular 
191 Malaysia, the Greater Sunda Islands, Borneo, Sulawesi, Muluccas, New Guinea, Cape York

192 Peninsula, the Solomon Islands, Vanuatu, New Caledonia, and Fiji. Suitable niches of $N$.

193 borneensis are located in Borneo, northern New Guinea, and Halmahera. Areas characterized

194 by less appropriate climatic conditions are also found in Sumatra and the Solomon Islands. The

195 potential range of $N$. veratrifolia includes Peninsular Malaysia, northern Sumatra, Palawan,

196 Mindanao, Sulawesi, Moluccas, central New Guinea, and the Solomon Islands. Some less

197 suitable niches are located in Borneo, Java, and Vanuatu. Habitats of $N$. zollingeri are

198 distributed in Laos, Vietnam, Peninsular Malaysia, the Nicobar Islands, Sumatra, Borneo, the

199 Philippines, Sulawesi, Moluccas, New Guinea, the Solomon Islands, Vanuatu, New Caledonia,

200 and Fiji, as well as on the northern coast of Australia, and the Solomon Islands. Figs 3-4.

201 Limiting factors and niches overlap

202 The distribution of all the studied species is related mostly with the mean diurnal range (Table

203 2). The second important climatic factor limiting the occurrence of apostasioid orchids is the

204 precipitation in the warmest quarter, which significantly influenced the models of the three

205 Apostasia species and Neuwiedia borneensis. The geographical ranges of Neuwiedia veratrifolia

206 and N. zollingeri are related with isothermality and the annual mean temperature. The latter

207 variable has a somewhat less significant contribution to the models of four other orchids.

208 The predicted niche occupancy graphs (Fig 5) showed that while most of the analyzed climatic

209 variables had a similar influence on the distribution of the studied species, some differences are

210 observed in preferences related to precipitation: the precipitation of the driest month (bio14),

211 precipitation seasonality (bio15), and the precipitation of the coldest quarter (bio19). Apostasia

212 species grows in regions with low precipitation values recorded in the driest month, while 
213 Neuwiedia representatives prefer rainfall of about $100-130 \mathrm{~mm}$ at this time of year. In the

214 aspect of precipitation seasonality the value of about 25 is preferred by most of the studied

215 species. However, three studied Apostasia representatives may also grow in areas

216 characterized by higher scores of this factor (about 80-85). While in the coldest quarter

217 Apostasia species prefer low amounts of rainfall, Neuwiedia representatives are adapted to

218 higher precipitation. The niches occupied by the studied Apostasia species did not overlap

219 significantly during LGM (Table 3). A. wallichii and A. odorata received the highest scores of

$220 D=0.603$ and $\mathrm{I}=0.849$. In the glacial period Neuwiedia representatives shared slightly more

221 habitats. The highest overlap $(D=0.600, \mathrm{I}=0.832)$ was calculated for $N$. zollingeri and $N$.

222 veratrifolia (Table 3). While within Apostasia the same pattern of niche commonality is

223 observed in the present time, the habitat overlap within Neuwiedia has changed (Table 4).

224 Currently, the highest niche overlap is observed for $N$. borneensis and $N$. veratrifolia $(D=0.577$,

$225 \mathrm{I}=0.854)$.

226 Interestingly, the tests indicated that the potential ranges of several of the studied species

227 overlap more significantly with representatives of other genera than their closest relatives.

228 During LGM N. borneensis and $N$. veratifolia shared most of their potential range area with $A$.

229 nuda and N. zollingeri with A. odorata. The same pattern is also observed at the present time.

230 The overlap of the suitable niches of some species has decreased since LGM, e.g. A. odorata

231 and A. nuda, A. nuda and N. zollingei, A. wallichii and A. odorata, N. borneensis and A. odorata,

$232 N$. veratifolia and $A$. odorata, N. veratifolia and $A$. wallichii, N. zollingeri and $A$. wallichii. In other

233 cases the potential ranges are currently more similar, e.g. A. wallichii and A. nuda, A. nuda and 
$234 N$. borneensis, A. nuda and N. veratifolia, N. zollingeri and A. odorata, N. borneensis - and $A$.

235 wallichii.

236

237

\section{Evolution of climatic tolerance and predicted niche occupancy (PNO)}

In this study the intra-specific variation was not addressed as it would require denser sampling

throughout the whole region. However, when accepting taxonomical backbone and treating species as being monophyletic assumption is made that there is no potential gene flow among taxa or possible diverse adaptations that are present within the intraspecific lineages. This may lead to some bias but currently available phylogenetic studies (Judd, Stern \& Cheadle, 1993;

Kocyan et al., 2004) suggest that it should be of minimal importance since there is no gene flow between species nor any visual signs of local adaptations. The phylogenetic tree with marked estimated divergence times is presented in S3 Figure.

The evolution of climatic tolerance (Fig 6) of all variables within the studied taxa indicated that Apostasia odorata developed somewhat broader ecological tolerance for four analyzed variables (bio1, bio5, bio8, bio13), in the case of another four (bio2, bio3, bio4, bio12) two species, A. odorata and Neuwiedia zollingeri, have distinctly broader tolerance. In relation to several climatic factors (bio14, bio18, bio19) all the studied species present similar tolerance. It is noteworthy that $A$. nuda shows similar preferences in the aspect of many climatic variables

252 (bio2, bio3, bio4, bio12, bio14, bio15 and bio19) to N. borneensis and N. veratifolia. In most cases the tolerance of the studied species' ancestors diverged a long time ago into two lineages: the first included Apostasia species and the other Neuwiedia, and among these two groups the diversification of their ecological tolerances began relatively recently. Furthermore, 
256 the presented predicted niche occupancy profiles show that most species have very similar

257 climatic requirements in respect to the studied variables, and deviations may be noted only in a 258 few cases (Fig 5).

259

260

Discussion

\section{Postglacial range changes}

262

263

264

265
The ENM analysis did not indicate any significant changes in the distribution of the suitable niches of most of the studied taxa. The highest congruence is observed in the potential glacial and current ranges of Neuwiedia borneensis and Neuwiedia zollingeri. ENM analysis indicated a minor loss of areas characterized by suitable niches in Apostasia odorata and Neuwiedia veratrifolia. A slight extension of the potential range is observed in Apostasia nuda and $A$. wallichii. The second species probably occupied niches of lower suitability during the LGM. Information provided in the atlas of palaeovegetation (Adams \& Faure, 1997) indicated that all the studied species occupied areas covered by tropical rainforest and monsoon or dry forest during the LGM. Apostasia odorata and A. wallichii could have also occurred in relatively low, usually deciduous tropical woodlands. Potential glacial refugia of Apostasia nuda and Neuwiedia veratrifolia were also located in savannas. Apostasia odorata could also have survived the glacial period in montane tundra, grassland and semi-arid temperate woodlands or scrublands. The available data on the current distribution of the studied species are consistent with the habitat preferences during the LGM, and no significant shift is observed in any of these orchids. This would partially explain the lack of extensive migration after the glacial period. 


\section{Potential vs documented geographical ranges}

279 The potential range of the studied species was compared with the current knowledge on their geographic distribution. While the models overlap mostly in the regions from which those

orchids have been reported, we found several incongruences between ENM outcomes and

floristic data. Smaller islands of Melanesia and Polynesia were indicated in the analysis as regions suitable for Apostasia odorata, A. wallichii and Neuwiedia zollingeri; however, we did not find any information on their occurrence in those areas. Additionally, we did not confirm the existence of Apostasia nuda or Neuwiedia borneensis in New Guinea, Neuwiedia zollingeri in the Philippines, or Apostasia odorata in Australia. Populations of Apostasia nuda were reported, inter alia, from Bangladesh, India, Cambodia and Vietnam, but ENM analysis did not

indicate continental south-east Asia as suitable for this species. This may be a result of the lack of occurrence data from this area included in the input dataset, and it would suggest that the continental populations grow in different climatic conditions from those distributed along the islands and in the Malay Peninsula.

The most probable reason for the inconsistencies between the potential and recognized geographical ranges of those species is the geographical and/or climatic barriers that prevent migration to suitable habitats across the sea (Hosner et al., 2014). On the other hand, we cannot exclude the extinction of some populations in their refugia localized on small islands after deglaciation and sea level rising (Dávalos \& Russell, 2012). In this situation there would be no progenitors in some parts of the potential ranges of the studied species. It should also be 
298

299

300

301

302

303

304

305

306

307

308

309

310

311

312

313

314

315

316

emphasized that the floristic data from numerous island groups are relatively obscure, and the populations of Apostasioideae representatives may be found in those regions in the future.

\section{Niche conservatism and evolution of climatic tolerance}

The niche conservatism of Apostasioideae is relatively high, and the tolerances of the studied climatic variables of the representatives of this group are rather narrow. The only species which may survive in a broader range of climatic factors is Apostasia odorata. Our studies indicated that the distribution of both Apostasia and Neuwiedia is limited by the same variable - the mean diurnal range. Moreover, within the examined orchids the overlap of their potential ranges is high, and in some cases representatives of Apostasia shares more habitats with Neuwiedia than with other congeners.

The reconstructed evolution of climatic tolerances of the studied species indicated that after the initial divergence of separated lineages of Apostasia and Neuwiedia the differentiation of the climatic niches within both genera began. Separation between the two genera occurred approximately 43-41 Ma ago (Gustafsson, Verola \& Antonelli, 2010) while the diversification of currently recognized species started around 21 to 10 Ma ago (Guo et al., 2012). This pattern was also observed in other flowering plants, e.g. palaeotropical genus Pseuduvaria (Annonaceae; Su \& Saunders, 2009). In the time of divergence of Apostasioideae from other orchids, about 45 Ma ago (Hall, 2002) Australia began to move rapidly northward. Subduction of the Australian plate resumed beneath Indonesia, causing widespread volcanism at the active margin and producing chains of the Sunda Arc stretched from Sumatra, through Java and the north arm of Sulawesi, and continued into the western Pacific to join the Philippines-Halmahera 
320 Arc (Lohman et al., 2011). This island chain could be colonized during several events and as

321 proven by Tänzler et al. (2016) the in situ diversification on different segments of the Sunda Arc

322 occurred. The speciation within studied genera was most probably a consequence of the

323 collision of Sahul and Sunda in the mid-Miocene that resulted also in the emergence of much of

324 the existing land east of Wallace's Line (Morley, 1998). Moreover, a second collision event

325 initiated in western New Guinea, creating the Central Range orogeny (Cloos et al., 2005;

326 Baldwin, Fitzgerald \& Webb, 2012).

327 The niche conservatism within Orchidaceae remains poorly recognized and previous studies

328 were focused mostly on invasive species (e.g. Kolanowska, 2013, Kolanowska \& Konowalik,

329 2014). The degree to which plants and animals retain their ancestral ecological traits plays

330 essential role in speciation, however in many orchids this pattern may be misinterpreted and

331 the phylogenetic niche conservatism signal may be disturbed by other factors promoting

332 evolution of new species, especially role of pollinators. As assumed by Ramírez (2007)

333 pollination in Apostasioideae must be accidental and the speciation within this group was

334 apparently not related to pollinator specificity. For this reason apostasioid orchids are ideal

335 model for testing niche conservatism using ENM and molecular data. While the revealed

336 pattern cannot be extrapolated into other Orchidaceae it brings important information on the

337 ecological differentiation in the earliest stage of orchid evolution.

338

339 Acknowledgments 
340 The curators and staff of the cited herbaria are thanked for access to their collections. We are

341 grateful to Sławomir Nowak for providing occurrence records of apostasioid orchids from New

342 Guinea and adjacent areas.

343 We acknowledge the World Climate Research Programme's Working Group on Coupled

344 Modelling, which is responsible for CMIP, and we thank National Center for Atmospheric

345 Research for producing and making available their model output. For CMIP the U.S. Department

346 of Energy's Program for Climate Model Diagnosis and Intercomparison provides coordinating

347 support and led development of software infrastructure in partnership with the Global

348 Organization for Earth System Science Portals.

\section{References}

351 Adams JM, Faure H. 1997. Review and Atlas of Palaeovegetation: Preliminary land ecosystem

352 maps of the world since the Last Glacial Maximum; Available from:

http://www.esd.ornl.gov/projects/qen/adams1.html

Baldwin SL, Fitzgerald PG, Webb LE. Tectonics of the New Guinea region. Annu Rev Earth

Planet Sci. 2012;40:495-520.

Barve N, Barve V, Jimenez-Valverde A, Lira-Noriega A, Maher SP, Peterson AT, Soberóna J,

357 Villalobosb F.The crucial role of the accessible area in ecological niche modeling and species

358 distribution modeling. Ecol Model. 2011;222:1810-1819.

Boria RA, Olson LE, Goodman SM, Anderson RP. Spatial filtering to reduce sampling bias can improve the performance of ecological niche models. Ecol Model. 2014;275:73-77. 
361 Cannon CH, Morley RJ, Bush AB. The current refugial rainforests of Sundaland are

362 unrepresentative of their biogeographic past and highly vulnerable to disturbance. Proc Natl

363 Acad Sci USA. 2009;106:11188-11193.

364 Cloos M, Sapiie B, Quarles van Ufford A, Weiland RJ, Warren PQ, McMahon TP. Collisional

365 delamination in New Guinea: the geotectonics of subducting slab breakoff. Geol Soc Spec Pap.

$366 \quad 2005 ; 400: 1-51$.

367 Darriba D, Taboada GL, Doallo R, Posada D. jModelTest 2: more models, new heuristics and 368 parallel computing. Nat Meth. 2012;9:772.

369 Dávalos LM, Russell AL. Deglaciation explains bat extinction in the Caribbean. Ecol Evol.

$370 \quad 2012 ; 2(12): 3045-3051$.

371 Elith J, Graham CH, Anderson RP, Dudík M, Ferrier S, Guisan A, Hijmans RJ, Huettmann F,

372 Leathwick JR, Lehmann A, Li J, Lohmann LG, Loiselle BA, Manion G, Moritz C, Nakamura M, 373 Nakazawa Y, McC. M. Overton J, Peterson AT, Phillips SJ, Richardson K, Scachetti-Pereira R, 374 Schapire RE, Soberón J, Williams S, Wisz MS, Zimmermann NE. Novel methods improve 375 prediction of species' distributions from occurrence data. Ecography. 2006;29:129-151. 376 Elith J, Phillips SJ, Hastie T, Dudík M, Chee YE, Yates CJ. A statistical explanation of MaxEnt for 377 ecologists. Divers Distrib. 2011;17:43-57.

378 Evans ME, Smith SA, Flynn RS, Donoghue MJ. Climate, niche evolution, and diversification of the 379 "bird-cage" evening primroses (Oenothera, sections Anogra and Kleinia). Am Nat 2009; 173(2): $380 \quad 225-240$

381 Exon N, Kennett J, Malone M, Brinkhuis H, Chaproniere G, Ennyu A, Fothergill P, Fuller M, 382 Grauert M, Hill P, Janecek T, Kelly C, Latimer J, McGonigal K, Nees S, Ninnemann U, Nuernberg 
N, Touchard Y, Wei W, White T. Drilling reveals climatic consequences of Tasmanian Gateway Opening, Eos Trans AGU. 2002;83(23):253-259.

Guo Y-Y, Luo Y-B, Liu Z-J, Wang X-Q. Evolution and Biogeography of the Slipper Orchids: Eocene

Vicariance of the Conduplicate Genera in the Old and New World Tropics. PLoS ONE. 2012I7:

e38788. doi:10.1371/journal.pone.0038788

Gustafsson AL, Verola CF, Antonelli A. Reassessing the temporal evolution of orchids with new

fossils and a Bayesian relaxed clock, with implications for the diversification of the rare South

American genus Hoffmannseggella (Orchidaceae: Epidendroideae). BMC Evol Biol. 2010;10:177.

Hall R. Cenozoic geological and plate tectonic evolution of SE Asia and the SW Pacific:

computer-based reconstructions, model and animations. J Asian Earth Sci. 2002; 20:353-434.

Hall R. The palaeogeography of Sundaland and Wallacea since the Late Jurassic. J Limnol.

2013;72(s2):1-17.

Hall R, Cottam MA, Wilson MEJ. The SE Asian Gateway. History and Tectonics of the Australia-

Asia Collison. London: The Geological Society; 2011.

Heibl C, Calenge C. Phyloclim: Integrating Phylogenetics and Climatic Niche Modeling. R

package version 0.9-4; 2013. http://CRAN.R-project.org/package=phyloclim

Hijmans RJ, Cameron SE, Parra JL, Jones PG, Jarvis A. Very high resolution interpolated climate surfaces for global land areas. Int J Climatol. 2005;25:1965-1978.

402

Hijmans RJ, Schreuder M, De La Cruz J, Guarino L. Using GIS to check co-ordinates of genebank accessions. Genet Resour Crop Evol. 1999;46:291-296. 
404 Hosner PA, Sánchez-González LA, Peterson AT, Moyle RG. Climate-driven diversification and 405 pleistocene refugia in Philippine birds: evidence from phylogeographic structure and 406 paleoenvironmental niche modeling. Evolution 2014;68:2658-2674.

407 Jersáková J, Trávníček P, Kubátová B, Krejčíková J, Urfus T, Liu Z-J, Lamb A, Ponert J, Schulte K, 408 Čurn V, Vrána J, Leitch IJ, Suda J. 2013. Genome size variation in the subfamily Apostasioideae: 409 filling the phylogenetic gap in orchids. Bot J Linn Soc. 2013;172:95-105.

410 Judd WS, Stern WL, Cheadle VI. Phylogenetic position of Apostasia and Neuwiedia

411 (Orchidaceae). Bot J Linn Soc. 1993;113:87-94.

412 Jukes T, Cantor C. Evolution of protein molecules. In: Munro H (ed) Mammalian Protein 413 Metabolism. Academic Press, New York, 1969; pp 21-132.

414 Katoh K, Toh H. Recent developments in the MAFFT multiple sequence alignment program. 415 Brief Bioinform 2008; 9: 286-298.

416 Kocyan A, Endress PK. Floral structure and development of Apostasia and Neuwiedia 417 (Apostasioideae) and their relationships to other Orchidaceae. Int J Plant Sci. 2001; 162:847418867.

419 Kocyan A, Qiu YL, Endress PK, Conti E. A phylogenetic analysis of Apostasioideae (Orchidaceae)

420 based on ITS, trnL-F and matK sequences. Plant Syst Evol. 2004;247:203-213.

421 Kolanowska M, Konowalik K. Niche Conservatism and Future Changes in the Potential Area 422 Coverage of Arundina graminifolia, an Invasive Orchids Species from Southeast Asia. Biotropica. $423 \quad 2014 ; 46: 157-165$.

424 Kolanowska M. Niche Conservatism and the Future Potential Range of Epipactis helleborine 425 (Orchidaceae). PLoS ONE. 2013;8:e77352. 
426 Mason SJ, Graham NE. Areas beneath the relative operating characteristics (ROC) and relative 427 operating levels (ROL) curves : Statistical significance and interpretation. Q.J.R. Meteorol Soc. $428 \quad 2002 ; 128: 2145-2166$.

429 Morley RJ. Palynological evidence for Tertiary plant dispersals in the South-east Asian region in 430 relation to plate tectonics and climate. In: Hall R, Holloway J, editors. Biogeography and 431 Geological Evolution of SE Asia. Leiden: Backhuys; 1998. p. 211-234.

432 Naczk AM, Kolanowska M. Glacial refugia and future habitat coverage of selected Dactylorhiza 433 representatives (Orchidaceae). PLoS One. 2015;10:e0143478.

434 Nordström S, Hedrén M. Genetic differentiation and postglacial migration of the Dactylorhiza 435 majalis ssp. traunsteineri/lapponica complex into Fennoscandia. Plant Syst Evol. 2008;276:7343687.

437 O'Connell J, Allen J, Hawkes K. Pleistocene Sahul and the origins of seafaring. In: Anderson A, 438 Barrett J, Boyle K, editors. The Global Origins and Development of Seafaring. Cambridge:

439 McDonald Institute for Archaeological Research; 2010. p. 57-68.

440 Paradis E, Claude J, Strimmer K. APE: analyses of phylogenetics and evolution in R language. 441 Bioinformatics 2004; 20: 289-290.

442 Phillips SJ, Anderson R, Schapire RE. Maximum entropy modeling of species geographic 443 distributions. Ecol Model. 2006;190:231-259.

444 Phillips SJ, Dudík M, Schapire RE. A maximum entropy approach to species distribution 445 modeling. In: ICML '04. Proceedings of the twenty-first international conference on Machine 446 learning. New York: ACM; 2004. p. 655-662. 
447 Ramírez SR, Gravendeel B, Singer RB, Marshall CR, Pierce NE. Dating the origin of the

448 Orchidaceae from a fossil orchid with its pollinator. Nature. 2007;448:1042-1045.

449 Ramírez W. Pollination analogies between Orchidaceae, Ficus (Moraceae) and Asclepiadaceae.

450 Lankesteriana. 2015;7:450-457.

451 Ronquist F, Teslenko M, van der Mark P, Ayres DL, Darling A, Höhna S, Larget B, Liu L, Suchard 452 MA, Huelsenbeck JP. MrBayes 3.2: efficient bayesian phylogenetic inference and model choice 453 across a large model space. Syst Biol 2012; 61(3): 539-542

454 Sanderson MJ. Estimating absolute rates of molecular evolution and divergence times: a 455 penalized likelihood approach. Molecular Biology and Evolution. 2002;19, 101--109.

456 Stern WL, Cheadle VI, Thorsch J. Apostasiads, systematic anatomy, and the origins of 457 Orchidaceae. Bot J Linn Soc. 1993;111:411-455.

458 Su YCF, Saunders RMK. Evolutionary divergence times in the Annonaceae: evidence of a 459 late Miocene origin of Pseuduvaria in Sundaland with subsequent diversification in New Guinea. 460 BMC Evol Biol. 2009;9:152. doi:10.1186/1471-2148-9-153

461 Szlachetko DL, Rutkowski P. Gynostemia Orchidalium. Vol. 1. Apostasiaceae, Cypripediaceae, 462 Orchidaceae (Thelymitroideae to Vanilloideae). Acta Bot Fennica. 2000;169:1-380.

463 Taylor KE, Stouffer RJ, Meehl GA. An Overview of CMIP5 and the experiment design. Bull Amer 464 Meteor Soc. 2012;93:485-498.

465 Tänzler R, Van Dam MH, Toussaint EFA, Suhardjono YR, Balke M, Riedel A. Macroevolution of 466 hyperdiverse flightless beetles reflects the complex geological history of the Sunda Arc. Sci Rep. $467 \quad 2016 ; 6: 18793$. 
468 Thiers B. Index Herbariorum: A global directory of public herbaria and associated staff. New

469 York Botanical Garden's Virtual Herbarium; 2015. Available from: http://sweetgum.nybg.org/ih/

470 van Hinsbergen DJ, Lippert PC, Dupont-Nivet G, McQuarrie N, Doubrovine PV, Spakman W,

471 Torsvik TH. Greater India Basin hypothesis and a two-stage Cenozoic collision between India

472 and Asia. Proc Natl Acad Sci USA. 2012;109:7659-7664.

473 Warren DL, Glor RE, Turelli M. ENMTools: a toolbox for comparative studies of environmental

474 niche models. Ecography. 2010;33:607-611.

475 Xinqi Ch, Gale SW, Cribb PJ. Apostasioideae. In: Wu ZY, Raven PH, Hong DY, editors. Flora of

476 China, Vol. 25. Beijing and St. Louis: Science Press and Missouri Botanical Garden Press; 2009. p.

$477 \quad 20-21$.

478 Young ND, Healy J. GapCoder automates the use of indel characters in phylogenetic analysis.

479 BMC Bioinformatics 2003; 4: 6

480 Yukawa T, Ogura-Tsujita Y, Shefferson RP, Yokoyama J. Mycorrhizal diversity in Apostasia

481 (Orchidaceae) indicates the origin and evolution of orchid mycorrhiza. Am J Bot. 2009;96:19974822009. 


\section{Table 1 (on next page)}

Table 1. Bioclimatic variables used in the ENM analysis. 
1 Table 1. Bioclimatic variables used in the ENM analysis.

\begin{tabular}{|l|l|}
\hline Code & Variable \\
\hline bio1 & Annual Mean Temperature \\
\hline bio2 & Mean Diurnal Range $=$ Mean of monthly (max temp - min temp) \\
\hline bio3 & Isothermality (bio2/bio7) (*100) \\
\hline bio4 & Temperature Seasonality (standard deviation *100) \\
\hline bio5 & Max Temperature of Warmest Month \\
\hline bio8 & Mean Temperature of Wettest Quarter \\
\hline bio12 & Annual Precipitation \\
\hline bio13 & Precipitation of Wettest Month \\
\hline bio14 & Precipitation of Driest Month \\
\hline bio15 & Precipitation Seasonality (Coefficient of Variation) \\
\hline bio18 & Precipitation of Warmest Quarter \\
\hline bio19 & Precipitation of Coldest Quarter \\
\hline
\end{tabular}

2 


\section{Table 2 (on next page)}

Table 2. Estimates of relative contributions of the three most important environmental variables to the Maxent models. 
1 Table 2. Estimates of relative contributions of the three most important environmental

2 variables to the Maxent models.

\begin{tabular}{|l|l|l|l|l|l|l|}
\hline & A. nuda & A. odorata & A. wallichii & N. & N. & N. zollingeri \\
\hline var_1 & bio2 (35.1) & bio2 (35.1) & bio2 (35.1) & bio2 (35) & bio2 (24.7) & bio2 (24.7) \\
\hline var_2 & bio18 (12.2) & bio18 (12.2) & bio18 (12.2) & bio18 (12.2) & bio1 (13.7) & bio1 (13.7) \\
\hline var_3 & bio1 (10.5) & bio1 (10.5) & bio1 (10.5) & bio1 (10.5) & bio3 (11.5) & bio3 (11.5) \\
\hline
\end{tabular}

3

4 


\section{Table 3 (on next page)}

Table 3. Results of niche overlap tests calculated for LGM. 
1 Table 3. Results of niche overlap tests calculated for LGM.

\begin{tabular}{|c|c|c|c|c|c|c|}
\hline$D \backslash I$ & A. nuda & A. odorata & A. wallichii & $\begin{array}{l}N . \\
\text { borneensis }\end{array}$ & $\begin{array}{l}\text { N. } \\
\text { veratrifolia }\end{array}$ & $\begin{array}{l}N . \\
\text { zollingeri }\end{array}$ \\
\hline A. nuda & $x$ & 0.627 & 0.689 & 0.940 & 0.891 & 0.783 \\
\hline A. odorata & 0.349 & $x$ & 0.849 & 0.560 & 0.670 & 0.924 \\
\hline A. wallichii & 0.410 & 0.603 & $x$ & 0.637 & 0.799 & 0.917 \\
\hline $\begin{array}{l}N . \\
\text { borneensis }\end{array}$ & 0.731 & 0.311 & 0.367 & $x$ & 0.816 & 0.736 \\
\hline $\begin{array}{l}N . \\
\text { veratrifolia }\end{array}$ & 0.641 & 0.398 & 0.518 & 0.527 & $x$ & 0.832 \\
\hline $\begin{array}{l}N . \\
\text { zollingeri }\end{array}$ & 0.528 & 0.704 & 0.710 & 0.475 & 0.600 & $x$ \\
\hline
\end{tabular}

2

3

4 


\section{Table 4(on next page)}

Table 4. Results of niche overlap tests calculated for the present time. 
1 Table 4. Results of niche overlap tests calculated for the present time.

\begin{tabular}{|l|l|l|l|l|l|l|}
\hline DVI & A. & A. & A. wallichii & N. borneensis & N. veratrifolia & N. zollingeri \\
\hline A. nuda & $\mathrm{x}$ & 0.548 & 0.730 & 0.966 & 0.912 & 0.712 \\
\hline A. odorata & 0.277 & $\mathrm{x}$ & 0.824 & 0.520 & 0.571 & 0.931 \\
\hline A. wallichii & 0.468 & 0.567 & $\mathrm{x}$ & 0.707 & 0.793 & 0.896 \\
\hline N. borneensis & 0.823 & 0.272 & 0.440 & $\mathrm{x}$ & 0.854 & 0.702 \\
\hline N. veratrifolia & 0.678 & 0.315 & 0.541 & 0.577 & $\mathrm{x}$ & 0.728 \\
\hline N. zollingeri & 0.463 & 0.715 & 0.663 & 0.456 & 0.485 & $\mathrm{x}$ \\
\hline
\end{tabular}

2 
Figure 1

Fig 1. Distribution of the suitable climatic niches of Apostasia species during LGM: $A$. nuda (A), A. odorata (B), and A. wallichii (C).

Map was prepared by the authors using ArcGIS software.

A

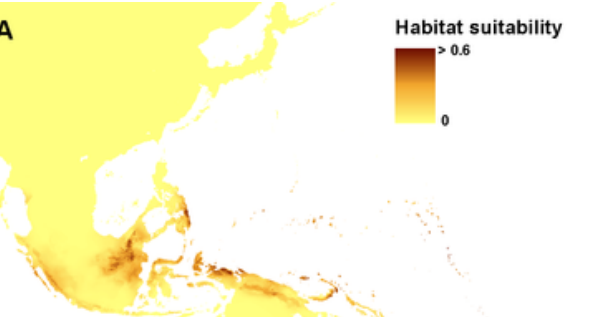

B

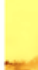

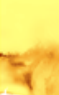

6
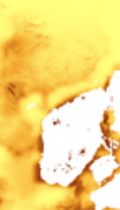

s

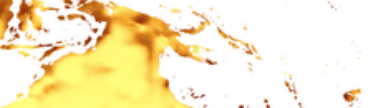

C

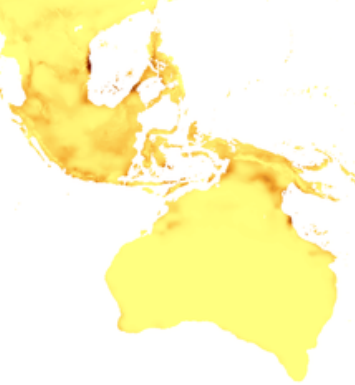


Figure 2

Fig 2. Distribution of the suitable climatic niches of Neuwiedia species during LGM: $N$. borneensis (A), N. veratrifolia (B), and N. zollingeri (C).

Map was prepared by the authors using ArcGIS software.

A

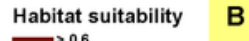

$>0.6$

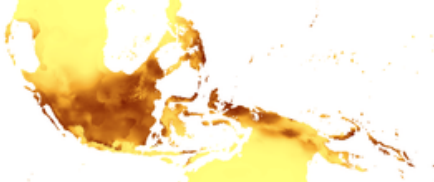

C

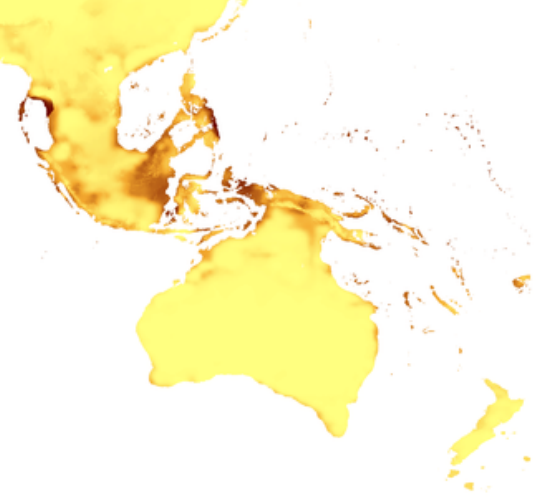


Figure 3

Fig 3. Current distribution of the suitable climatic niches of Apostasia species: $A$. nuda (A), A. odorata (B), and A. wallichii (C).

Spots indicate the localities used in ENM analysis. Map was prepared by the authors using ArcGIS software.

A

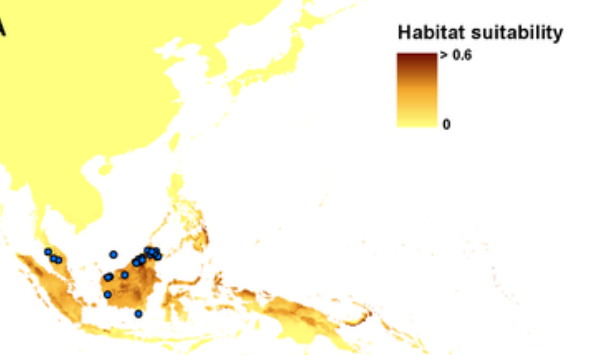

B

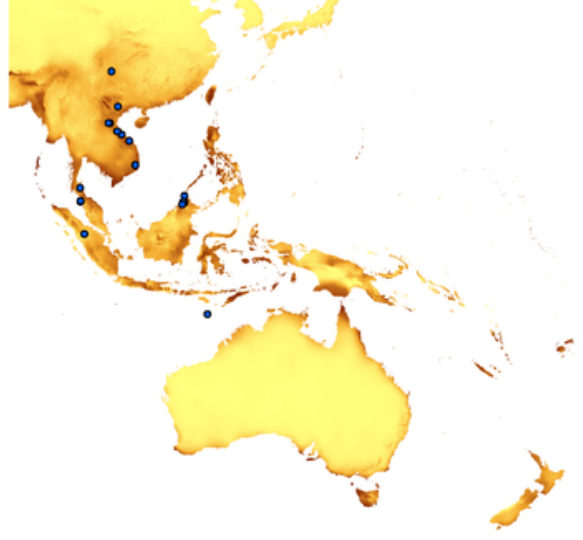

C

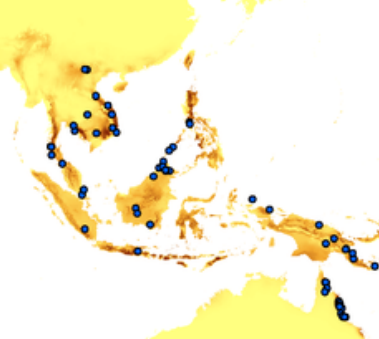




\section{Figure 4}

Fig 4. Current distribution of the suitable climatic niches of Neuwiedia species: $N$. borneensis (A), N. veratrifolia (B), and N. zollingeri (C).

Spots indicate the localities used in ENM analysis. Map was prepared by the authors using ArcGIS software.

A

Habitat suitability

$\rightarrow 0.6$

0
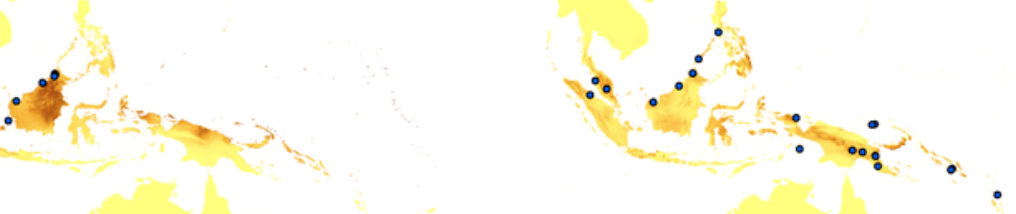

C

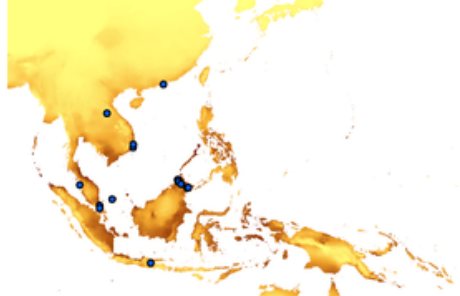


Figure 5

Fig 5. Predicted niche occupancy profiles of all studied species. 
Predicted niche occupancy
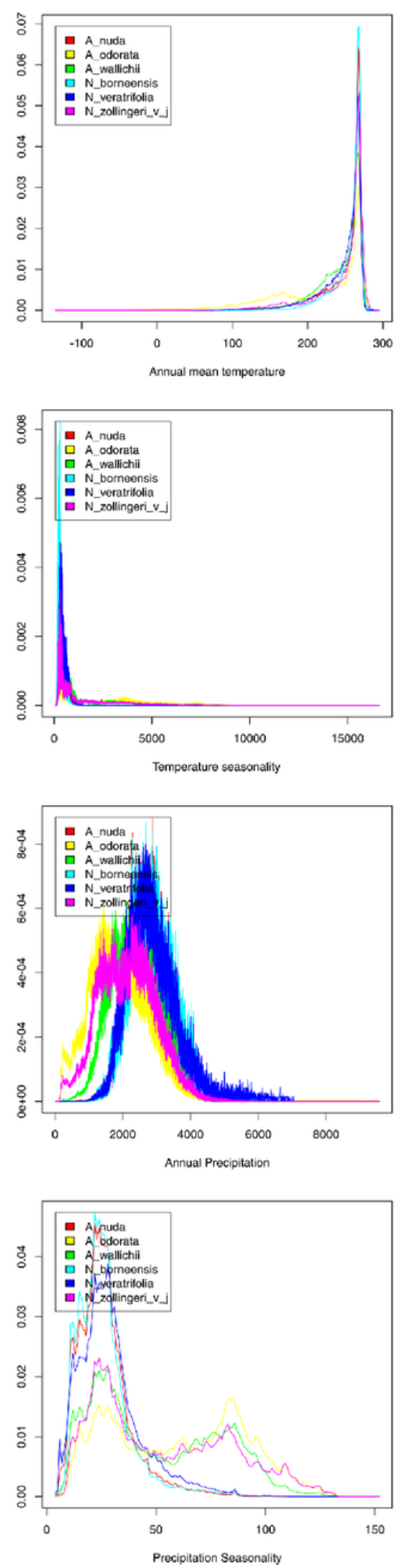

Predicted niche occupancy
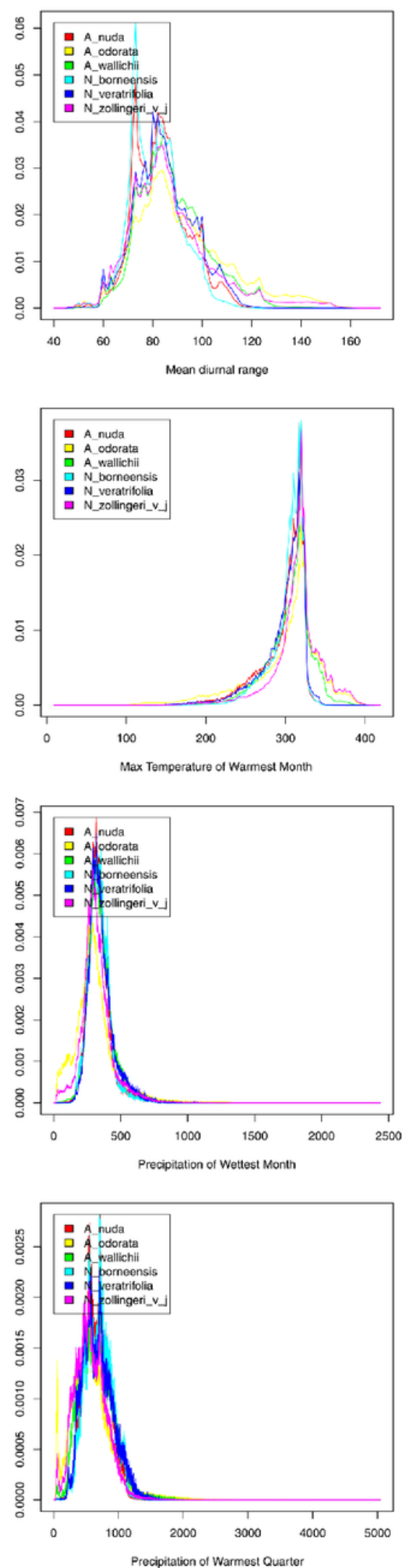

Predicted niche occupancy
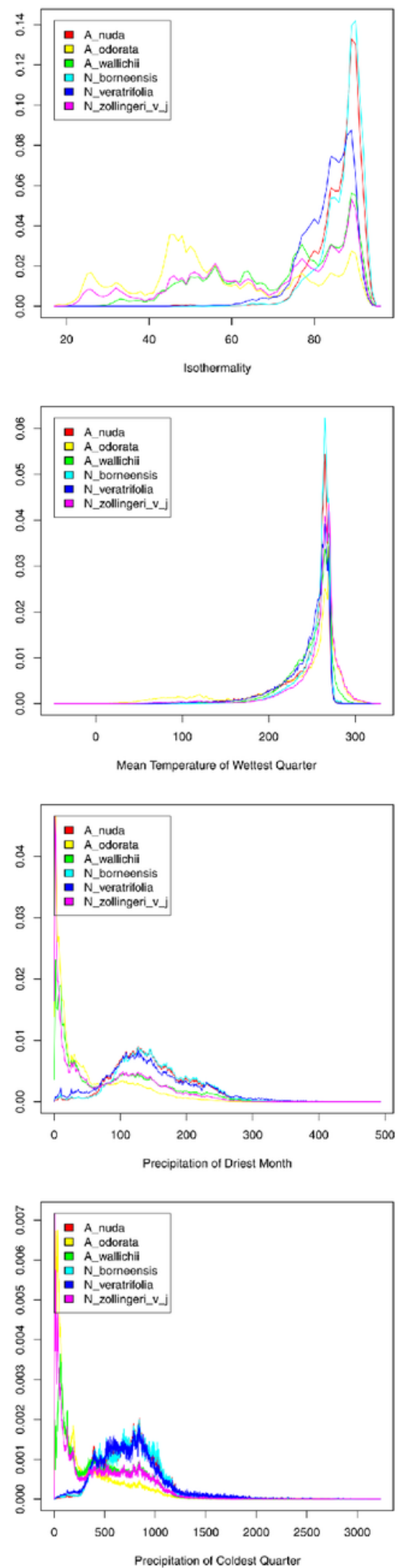


\section{Figure 6}

Fig 6. Evolution of ecological tolerances of all studied species.

Apostasia wallichii $=A_{-} w$, Apostasia odorata $=A_{-} 0$, Apostasia nuda $=A_{-} n$, Neuwiedia zollingeri $=N_{-} z$, Neuwiedia veratrifolia $=N_{-} v$, Neuwiedia borneensis $=N_{-} b$. 

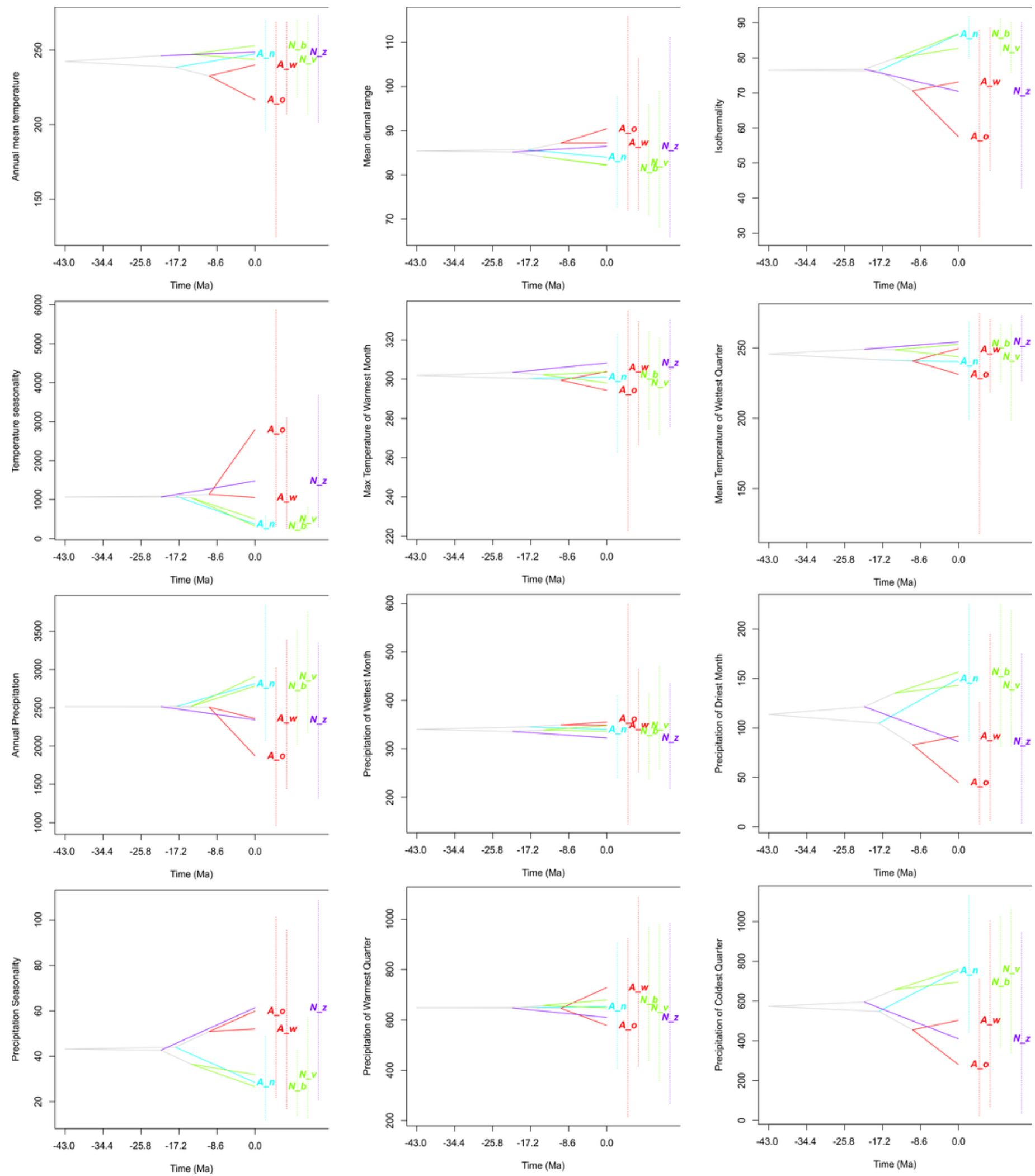